\title{
Gender differences in health status and benefits of a one-week educational program for caregivers of cancer patients
}

G. M. Gjerset PhD, Post-doctoral fellow ${ }^{1,4}$, M. Tendille MSc, Sport educator ${ }^{2}$, T. Skaali MD, PhD, Head of The Outpatient Cancer Rehabilitation Unit ${ }^{2}$, C. E. Kiserud MD, $\mathrm{PhD}$, Head of National Advisory Unit on Late Effects after Cancer Treatment ${ }^{1}$, A. A. Dahl MD, PhD, Professor emeritus ${ }^{1,3}$, S. B. Gudbergsson PhD, Research fellow ${ }^{4}$, L. Thorsen PhD, Research fellow ${ }^{1,5}$

${ }^{1}$ National Advisory Unit on Late Effects after Cancer Treatment, Department of Oncology, Division of Cancer Medicine, Oslo University Hospital, Oslo, Norway

${ }^{2}$ The Outpatient Cancer Rehabilitation Unit, Department of Clinical Service, Division of Cancer Medicine, Oslo University Hospital, Oslo, Norway

${ }^{3}$ University of Oslo, Oslo, Norway

${ }^{4}$ Montebello Center, The Norwegian Resource Center for Coping with Cancer, Mesnali, Norway.

${ }^{5}$ Department of Clinical Service, Division of Cancer Medicine, Oslo University Hospital, Oslo, Norway

\section{Corresponding author}

Gunhild M. Gjerset, PhD

National Advisory Unit on Late Effects after Cancer Treatment, Department of Oncology,

Division of Cancer Medicine, Oslo University Hospital

P.O. box 4953 Nydalen, 0424 Oslo, Norway

E-mail: gunhg@ous-hf.no

Phone: +4722935426

\section{Acknowledgements}

This project was funded by grant from Southern and Eastern Norway Regional Health Authority (Helse Sør-Øst RHF) and The Norwegian Radium Hospital Foundation. The authors wish to acknowledge the work and collaboration of the staff of the Montebello Center. 


\section{ABSTRACT}

Objective: The aims of this study were to investigate differences between female and male caregivers' health status before and three months after a one-week educational program, selfreported needs for support and changes in health status over time.

Methods: Caregivers were partners of cancer patients aged $\geq 18$ years who participated in the program. Questionnaires were completed at baseline and three months after the program.

Results: At baseline 167 caregivers completed the questionnaire, 55\% were females and the mean age 60.2 years (range $31-79)$. Female caregivers reported poorer vitality $(p=0.016)$ and more chronic fatigue compared to male caregivers ( $28 \%$ vs. $13 \%, \mathrm{p}=0.036)$. Females more frequently reported need for support; psychological counselling ( $21 \%$ vs. $3 \%, \mathrm{p}=0.001)$, group conversations ( $51 \%$ vs. $28 \%, \mathrm{p}=0.003)$, nutritional counselling ( $39 \%$ vs. $17 \%, \mathrm{p}=0.002)$ and recreational stay ( $46 \%$ vs. $24 \%, \mathrm{p}=0.004)$. Significant benefits within group changes were observed among female caregivers in role physical, general health, vitality, social functioning, mental and total fatigue, whereas no significant within group changes were observed for males. However, in adjusted analyses no significantly between-group gender differences in mean changes were observed.

Conclusion: More studies are needed to better understand the differences and possible effects of programs among female and male caregivers in order to develop relevant support. 


\section{INTRODUCTION}

The days as inpatients for cancer patients have been reduced over the last decades, and hospitalization has been replaced with outpatient consultations. These changes have led to an increased need for support to the cancer patients by their family and social network. Their partners are usually the closest people to take on the caregiver role (Waldron, Janke, Bechtel, Ramirez, \& Cohen, 2013). The caregivers' responsibilities, worries, coping, and active caring role can be a substantial burden (Kayser, Watson, \& Andrade, 2007). Cancer not only affects the patients, but also their caregivers (Kayser et al., 2007), thus the couple rather than two isolated persons, is affected (Hagedoorn, Sanderman, Bolks, Tuinstra, \& Coyne, 2008; Traa, De Vries, Bodenmann, \& Den Oudsten, 2015).

Caregivers of cancer patients can experience high levels of distress, potential burnout, depressive symptoms, poor health, and unmet needs for support (Li, Mak, \& Loke, 2013). The distress can be as high, or even higher, as compared with the patient (Northouse, Mood, Templin, Mellon, \& George 2000; Hagedoorn et al., 2008). The potential health problems of caregivers are complex, but a strong predictor of distress is gender (Ussher \& Sandoval, 2008), and female caregivers often experience more health impairments than males (Li et al., 2013; Moser, Kunzler, Nussbeck, Bargetzi, \& Znoj, 2013; Li \& Loke, 2013; Valeberg \& Grov, 2013). Being a female caregiver represents a higher risk for developing depression, sleep problems, fatigue and caregiver burden compared to male caregivers (Stenberg, Cvancarova, Ekstedt, Olsson, \& Ruland, 2014).

A systematic review of psychosocial interventions claims that support and education may be the most effective tools for improving health-related quality of life (HRQoL) for caregivers of cancer patients (Waldron et al., 2013), but there is limited knowledge on gender differences concerning the benefits of such programs for caregivers. 
The Montebello Center (MBC) is a Norwegian resource center for coping with cancer, and has for the last 25 years included caregivers of cancer patients into their one-week educational programs. The participation rate of couples is high, but systematic studies of the benefits for caregivers have not been conducted.

The aims of this study were to investigate differences between female and male caregivers regarding: 1) health status at the start of the one-week educational program and at three months after termination, 2) self-reported needs for support at the start of the program, and 3) changes in health status from the start to three months after termination of the program.

\section{MATERIAL AND METHODS}

\section{Caregiver sampling}

At the MBC between September 2011 and February 2013, 304 caregivers of cancer patients were invited to the study. Caregivers were recruited from the one-week diagnosis-specific programs including patients with breast-, prostate-, and gastro-intestinal cancer. Inclusion criterion for caregivers was age $\geq 18$ years.

Among the 304 caregivers invited, 191 participated (63\% acceptance rate) and completed the baseline questionnaire. For the present analyses we only included caregivers defined as partners, and caregivers such as friends, children, or parents were excluded $(\mathrm{N}=24)$, leaving 167 partners as our baseline sample. Three months after program termination, the baseline sample was addressed with a mailed questionnaire, and 115 caregivers (69\% of participants) responded to the follow-up (Figure 1).

\section{The educational programs at the $\mathrm{MBC}$}

The MBC has offered educational programs to cancer patients and their caregivers since 1990 . The aims of all programs are to improve knowledge of cancer and to learn coping strategies 
concerning the relevant malignancy and its side- and late effects through lectures, group sessions, and physical activities. The various cancer specific programs are led by multidisciplinary teams comprised of oncologists, nurses, psychologists, physiotherapists/sport instructors, nutritionists, and social workers. During the programs, the caregivers participate along with their partner and learn about different cancer-related topics through lectures. All programs include five separate group sessions for caregivers. Physical activity is offered (on voluntary basis) in groups led by a physiotherapist or a sport instructor. Physical activities include two to three morning walks (with or without poles) and additional activities such as water gymnastics, resistance training, stretching and relaxation. Besides all planned activities, patients and caregivers share their meals and social settings in the evenings.

\section{Normative data}

Normative data of the Norwegian population regarding fatigue (Loge, Ekeberg, \& Kaasa 1998) and HRQoL (Loge \& Kaasa, 1998) were implemented in the discussion section to compare the caregivers' health status in our sample.

\section{Assessments}

All data were self-reported by a questionnaire, which the caregivers completed at start (baseline) and three months after termination of the education week (follow-up).

\section{Background variables}

The questionnaire covered sociodemographic variables such as age at baseline, education ( $\leq$ 12 years/>12 years), and having children (yes/no). Current work situation was operationalized as "being in paid work or not" which meant that either the caregiver was employed or selfemployment either full or part time, while not being in paid work implied disability pension, 
retirement pension, or being on social support. Information on partners' cancer related variables regarding the partners': cancer diagnosis, time since diagnosis (months) and recurrence of cancer or metastasis (yes/no) was covered. Medical conditions were measured by questions regarding cardiovascular diseases including myocardial infarction, angina pectoris, stroke and/or diabetes and musculoskeletal diseases covering osteoporosis, fibromyalgia, arthrosis and/or other longterm skeletal- or muscle diseases. Physical and psychological illnesses were defined as sickness, injuries, or disorders for a year or longer that limits their function in daily life.

\section{$\underline{\text { Health variables }}$}

\section{HRQoL}

HRQoL was measured by the Medical Outcomes Study Short Form 36 (SF-36), which consists of eight subscales of HRQoL (physical functioning, role limitations due to physical problems, bodily pain, general health, vitality, social functioning, role limitation due to emotional problems and mental health). The responses to items within the eight dimensions were summed and transformed to $0-100$ scales $(0=$ worst health state, $100=$ best health state $)$. From these eight dimensions a physical component score (PCS) and mental component score (MCS) can be provided, and a mean of 50 with a standard deviation of 10 represents the population norm (Ware, 2000).

HRQoL was also assessed by two questions constituting the global QoL, which were part of The European Organization for Research and Treatment of Cancer Core Quality of Life Questionnaire C-30 (EORTC QLQC30) (Aaronson et al., 1993). These two questions asked about caregivers overall HRQoL and overall health condition, providing a global HRQoL score. The score ranged from 0-100, where the higher score indicated better HRQoL. 


\section{Fatigue}

Fatigue was self-rated by the The Fatigue Questionnaire which consisted of seven items regarding physical fatigue and four items concerning mental fatigue during the last month. Each question had four response alternatives, rated on a Likert scale from 0-3. The scores for physical fatigue (possible range 0-21) and mental fatigue (0-12) were summarized separately, and added together as total fatigue score (0-33). Higher score implies more fatigue (Chalder et al., 1993). A dichotomized score $(0-1=0$ and 2-3 = 1) is used for the definition of chronic fatigue, which is defined as a sum of dichotomized score of $\geq 4$ and duration for $\geq 6$ months.

\section{Lifestyle}

Body mass index (BMI) was calculated based on the caregivers' weight (kg) divided by the square of the height (meters), and overweight was defined as BMI $\geq 25 \mathrm{~kg} / \mathrm{m}^{2}$ and obesity as $\mathrm{BMI} \geq 30 \mathrm{~kg} / \mathrm{m}^{2}$. Current smoker was defined as a person who smokes daily or occasionally. An alcohol intake $\geq 2$ times per week was defined as frequent alcohol use. Physical activity level was measured by three questions concerning frequency, intensity, and duration. These three components were calculated into a physical activity index ranged from 0 (no activity) to 15 (maximum activity), according to the algorithm of Kurtze et al. 2008 (Kurtze, Rangul, \& Hustvedt 2008).

\section{Influence on work situation and family life}

The caregivers responded to questions regarding the influence on work situation and family life caused by the malignancy of their partners. The questions were respectively: "Has the partners' cancer disease changed your work situation?" (yes/no) and "To which extent has the cancer disease affected your family life?" (“To a very large extent", "Large extent", "To a certain extent", "To a small extent" or "Not affected"). The latter response alternatives were 
dichotomized so that "Yes" covered "To a very large"/"Large Extent", and "No" contained the remaining alternatives.

\section{$\underline{\text { Needs for support }}$}

At baseline the caregivers responded to current supportive needs ("Yes"/"No"/"Do not know") regarding consultation with a psychologist, group conversations with other caregivers, nutritional counselling and a recreational stay (1-4 weeks).

\section{Statistics}

To detect significant differences in background variables between the genders at baseline and follow-up, Independent sample t-tests, Non-parametric Mann-Whitney U tests and chi-square tests were used on continuous data and categorical variables. Gender differences in health variables and influence on work situation and family life were adjusted for background variables that significantly differed between the genders at baseline by using multivariate linear regression analyses for continuous variables and logistic regression analyses for categorical variables. Both musculoskeletal diseases and longterm physical illness were significant different in men compared to women at baseline, but since these two variables were highly associated only musculoskeletal diseases were included in the final multivariate model.

A paired sampled t-test was conducted to examine the mean change within group (genders) from baseline to follow-up. Between group differences in mean change from baseline to follow-up were assessed by analysis of covariance (ANCOVA) with the change score from baseline to follow-up included as the dependent variable, gender as fixed factor and baseline score and background variables that significantly differed between the gender at baseline as covariates. 
To calculate differences between our data and the normative mean values from Norwegian population samples we used one-sample t-test.

The statistical significance value was $\mathrm{p}<0.05$, and all tests were two-sided. All statistical analyses were performed using the IBM SPSS Statistics, version 21 (IBM Inc., Armonk, NY, USA).

\section{Ethics}

The regional committee for Medical and Health Research Ethics of South-East Norway approved this study (REK number 2010/1132), and all participants gave written informed consent.

\section{RESULTS}

\section{Participant characteristics}

Among the 167 participants who completed the questionnaire at baseline, $92(55 \%)$ were female caregivers and $75(45 \%)$ were males. Average age at baseline was 61.4 years (SD 8.8) for females and 58.8 years (SD 9.3) for males. More female than male caregivers reported that their partner had recurrence of cancer or metastasis $(\mathrm{p}=0.008)$, and statistically significant more female caregivers reported musculoskeletal diseases $(\mathrm{p}<0.001)$ and longterm physical illness $(\mathrm{p}=0.03)$ than male caregivers (Table 1$)$. Other baseline data of their sociodemographic variables, medical conditions, HRQoL, fatigue, lifestyle and influence on work situation and family life are presented in Table 1.

An attrition analysis comparing 52 non-responding caregivers at follow-up versus 115 participants, showed no significant differences between these groups regarding baseline variables and needs (data not shown). 


\section{Health status at baseline}

At baseline, adjusted for the partners' recurrence of cancer or metastasis and musculoskeletal diseases, female caregivers reported statistically significant lower scores on vitality, and borderline statistically significant lower scores on bodily pain, general health and mental health compared to male caregivers. Female caregivers had also a statistically significant higher prevalence of chronic fatigue $(28 \%$ vs. $13 \%, \mathrm{p}=0.036)$ than male caregivers (Table 1$)$.

Adjusted for the partners' recurrence of cancer or metastasis and musculoskeletal diseases, a statistically significant higher rate of male caregivers reported that their partners' cancer disease had changed their work situation $(14 \%$ vs. $5 \%, \mathrm{p}=0.03)$ and that their partners' cancer disease had affected their family life to a large or very large extent (53\% vs. $36 \%$, $\mathrm{p}=0.05$, borderline statistically significant) compared to female caregivers.

\section{Health status at follow-up}

At follow-up, adjusted for the partners' recurrence of cancer or metastasis and musculoskeletal diseases, female caregivers reported statistically lower scores on physical functioning than male caregivers (Table 2). Compared to female caregivers, more male caregivers still reported that their work situation had been changed due to the cancer (18\% vs. $3 \%, \mathrm{p}=0.055$, borderline statistically significant).

\section{Needs for support at baseline}

Compared to male caregivers, female caregivers reported more frequent need for psychological counselling ( $21 \%$ vs. $3 \%$, p<0.001), group conversations with other caregivers ( $51 \%$ vs. $28 \%, \mathrm{p}=0.003)$, nutritional counselling ( $39 \%$ vs. $17 \%, \mathrm{p}=0.002)$ and a recreational stay (46\% vs. $24 \%, \mathrm{p}=0.004)$ (Figure 2 ). 


\section{Changes in health status from baseline to follow-up}

Within group mean changes showed statistically significant positive changes among female caregivers regarding their role limitations due to physical problems, general health, vitality, social functioning, mental fatigue score and total fatigue score, whereas physical fatigue score was borderline statistically significant (Table 3). No statistically significant within group changes were observed for male caregivers.

Adjusted for baseline values, the partners' recurrence of cancer or metastasis and musculoskeletal diseases, no between group differences in mean change in HRQoL, fatigue or physical activity variables were found.

\section{DISCUSSION}

The present study showed that female caregivers reported lower scores on vitality than males at the start of the one-week educational program. Further a higher proportion of the female caregivers reported chronic fatigue than the males. Female caregivers also appeared to have more need for support than male caregivers did, while a higher proportion of male caregivers reported that their work situation had been affected due to the cancer. Three months after termination of the program, female caregivers reported poorer physical functioning compared with male caregivers.

Our results regarding female caregivers experiencing more health problems than male caregivers are consistent with previous findings (Li et al., 2013; Li \& Loke, 2013; Stenberg et al., 2014). These results may indicate that female caregivers are considerably more affected by the caregiver situation concerning their physical and psychological health than the male ones. It should be investigated further if gender differences between cancer caregivers are related to differences in resilience or coping strategies. The findings can be interpreted in the way that female caregivers usually react more emotionally to their role, while males have 
more focus on practical changes, which could be of relevance for future planning of the educational program. A meta-analysis found that females are more likely to focus on emotions as a coping strategy than males do when coping with stress (Tamres et al., 2002). Folkman and Lazarus (1980) suggested that males use more problem-focused strategies compared to females.

For a deeper understanding of our results, we compared the data with findings from Norwegian population samples. We observed that our female caregivers at baseline showed significantly poorer bodily pain, general health, vitality, social functioning and mental health compared to Norwegian women (Loge \& Kaasa, 1998). At follow-up only bodily pain and mental health was significantly poorer, which may indicate that the female caregivers have improved several HRQoL variables, since the gaps between them and the normative mean scores were smaller. The proportion with chronic fatigue and mean fatigue scores were significantly higher among female caregivers both at baseline and follow-up compared to samples of Norwegian women (Loge et al., 1998). The HRQoL among the male caregivers did not differ significantly from findings of the male normative samples at baseline (Loge \& Kaasa, 1998). The proportion with chronic fatigue and all mean fatigue scores were significantly higher among male caregivers compared to samples of Norwegian men at baseline. At follow-up physical fatigue and proportion with chronic fatigue were still higher compared to the Norwegian men (Loge et al., 1998).

Three months after termination of the educational program, several significant positive changes were observed within female caregivers, whereas these changes were not observed within the males. However, no significant between group differences in HRQoL, fatigue or physical activity emerged. This might imply that higher baseline levels of distress prior to the intervention followed by greater potential for improvement could explain this change in female caregivers rather than gender differences. The comparisons to the Norwegian 
population samples concerning HRQoL may indicate that the male caregivers in our sample do not need support in the same extent as the females, and a "ceiling-effect" from an educational program like this can limit the improvements when their health status is roughly normal. Nevertheless, it might be that the participation of the male caregivers is useful in terms of supporting their partners. If the positive changes among the female caregivers are caused by the educational program is not clear, but it is promising to observe that females' HRQoL and fatigue scores significantly improved over time.

\section{Limitations}

A limitation of the study is the lack of a measure on coping and self-efficacy, which may have provided useful information on impacts of the intervention on caregivers' perceived selfefficacy in caregiving. Data on differences between the partners' primary treatment, sideeffects and coping after diagnosis could have enriched our study. The interpretations of our results should be done with care due to our small samples with increased risk of type II statistical errors.

\section{CONCLUSIONS}

The present study indicates that female caregivers had lower scores on vitality, more chronic fatigue and express a higher need for support than male caregivers at the start of an educational program. Significant benefits within group changes over time were observed among female caregivers, whereas no significant changes were observed for male caregivers. We observed no significant between gender differences in mean changes from baseline to follow-up. More studies are needed to better understand the differences and effects of programs among female and male caregivers in order to develop relevant support. This study indicates that female caregivers need more support than male caregivers and because of lower 
health status at baseline they may have more benefits of participating in an educational program.

\section{REFERENCES}

Aaronson N.K., Ahmedzai S., Bergman B., Bullinger M., Cull A., Duez N.J., \& Takeda F. (1993). The European Organization for Research and Treatment of Cancer QLQ-C30: a quality-of-life instrument for use in international clinical trials in oncology. Journal of the National Cancer Institute, 85, 365-376.

Chalder T., Berelowitz G., Pawlikowska T., Watts L., Wessely S., Wright D., \& Wallace P. (1993). Development of a fatigue scale. Journal of Psychosomatic Research, 37, 147153.

Folkman S., \& Lazarus R.S. (1980). An analysis of coping in a middle-aged community sample. Journal of Personality and Social Psychology, 21, 219-239.

Hagedoorn M., Sanderman R., Bolks H.N., Tuinstra J., \& Coyne J.C. (2008). Distress in couples coping with cancer: a meta-analysis and critical review of role and gender effects. Psychological Bulletin, 134 (1), 1-30.

Kayser K., Watson L.E., \& Andrade J.T. (2007). Cancer as a "We-Disease": Examining the Process of Coping From a Relational Perspective. Families Systems \& Health, 25, 404-418.

Kurtze N., Rangul V., \& Hustvedt B.E. (2008) Reliability and validity of the international physical activity questionnaire in the Nord-Trondelag health study (HUNT) population of men. BMC Medical Research Methodololgy. 8, 63.

Li Q., \& Loke A.Y. (2013). A spectrum of hidden morbidities among spousal caregivers for patients with cancer, and differences between the genders: a review of the literature. European Journal of Oncology Nursing, 17, 578-587. 
Li Q.P., Mak Y.W., \& Loke A.Y. (2013). Spouses' experience of caregiving for cancer patients: a literature review. International Nursing Review, 60, 178-187.

Loge J.H., Ekeberg O., \& Kaasa S. (1998). Fatigue in the general Norwegian population: normative data and associations. Journal of Psychosomatic Research, 45, 53-65.

Loge J.H., \& Kaasa S. (1998). Short form 36 (SF-36) health survey: normative data from the general Norwegian population. Scandinavian Journal of Social Medicine, 26, 250-258.

Moser M.T., Kunzler A., Nussbeck F., Bargetzi M., \& Znoj H.J. (2013). Higher emotional distress in female partners of cancer patients: prevalence and patient-partner interdependencies in a 3-year cohort. Psycho-Oncology, 22, 2693-2701.

Northouse L.L., Mood D., Templin T., Mellon S., \& George T. (2000). Couples' patterns of adjustment to colon cancer. Social Science and Medicine, 50, 271-284.

Stenberg U., Cvancarova M., Ekstedt M., Olsson M., \& Ruland C. (2014). Family caregivers of cancer patients: perceived burden and symptoms during the early phases of cancer treatment. Social Work in Health Care, 53, 289-309.

Tamres L., Janicki D., \& Helgeson V.S. (2002). Sex differences in coping behavior: A metaanalytic rewiev and an examination of relative coping. Personality and Social Psychology Review, 6 (1), 2-30.

Traa M.J., De Vries J., Bodenmann G., \& Den Oudsten B.L. (2015). Dyadic coping and relationship functioning in couples coping with cancer: a systematic review. British Journal of Health Psychology, 20, 85-114.

Ussher J.M., \& Sandoval M. (2008). Gender differences in the construction and experience of cancer care: the consequences of the gendered positioning of carers. Psychology and Health, 23, 945-963. 
Valeberg B.T., \& Grov E.K. (2013). Symptoms in the cancer patient: of importance for their caregivers' quality of life and mental health? European Journal of Oncology Nursing, $17,46-51$.

Waldron E.A., Janke E.A., Bechtel C.F., Ramirez M., \& Cohen A. (2013). A systematic review of psychosocial interventions to improve cancer caregiver quality of life. Psycho-Oncology, 22, 1200-1207.

Ware J.E. (2000). SF-36 Health Survey Update. SPINE, 25, 3130-3139. 
Table 1. Comparison between female $(\mathrm{N}=92)$ and male $(\mathrm{N}=75)$ caregivers at baseline

\begin{tabular}{|c|c|c|c|c|}
\hline Variables & $\begin{array}{c}\text { Total } \\
\mathrm{N}=167 \\
(100 \%)\end{array}$ & $\begin{array}{c}\text { Females } \\
\mathrm{N}=92 \\
(55 \%)\end{array}$ & $\begin{array}{l}\text { Males } \\
\mathrm{N}=75 \\
(45 \%)\end{array}$ & p-value \\
\hline \multicolumn{5}{|l|}{ Background variables } \\
\hline \multicolumn{5}{|l|}{ Sociodemographic variables } \\
\hline Age at baseline (years), mean (SD) & $60.2(9.1)$ & $61.4(8.8)$ & $58.8(9.3)$ & $0.07^{\mathrm{a}}$ \\
\hline Education > 12 years, $\mathrm{N}(\%)$ & $86(53)$ & $47(53)$ & $39(52)$ & $0.86^{\mathrm{b}}$ \\
\hline Have children $<18$ living at home, $\mathrm{N}(\%)$ & $17(10)$ & $6(7)$ & $11(15)$ & $0.09^{\mathrm{b}}$ \\
\hline Paid work at baseline, $\mathrm{N}(\%)$ & $88(54)$ & $42(47)$ & $46(61)$ & $0.07^{\mathrm{b}}$ \\
\hline \multicolumn{5}{|l|}{ Partners' cancer related variables } \\
\hline \multicolumn{5}{|l|}{ The partners' cancer diagnosis, $\mathrm{N}(\%)$} \\
\hline Breast & $70(42)$ & $4(4)$ & $66(88)$ & \\
\hline Prostate & $76(45)$ & $76(83)$ & $0(0)$ & \\
\hline Gastrointestinal & $21(13)$ & $12(13)$ & $9(12)$ & \\
\hline \multicolumn{5}{|l|}{ The partners' time since diagnosis (months), } \\
\hline Mean (SD) & $24.7(35.9)$ & $30.2(44.9)$ & $18.2(19.0)$ & \\
\hline Median (range) & $13.4(2-238)$ & $13.4(2-238)$ & $13.4(2-154)$ & $0.30^{\mathrm{c}}$ \\
\hline The partners' recurrence of cancer/metastasis, N (\%) & $40(25)$ & $29(34)$ & $11(15)$ & $0.008^{\mathrm{b}}$ \\
\hline \multicolumn{5}{|l|}{ Medical conditions, $\mathrm{N}(\%)$} \\
\hline Cardiovascular diseases & $23(14)$ & $13(14)$ & $10(13)$ & $0.88^{\mathrm{b}}$ \\
\hline Musculoskeletal diseases, & $60(36)$ & $49(53)$ & $11(15)$ & $<0.001^{\mathrm{b}}$ \\
\hline Physical illness (> 1 year) & $40(24)$ & $28(31)$ & $12(16)$ & $0.03^{\mathrm{b}}$ \\
\hline Psychological illness (> 1 year) & $17(10)$ & $10(11)$ & $7(9)$ & $0.71^{\mathrm{b}}$ \\
\hline \multicolumn{5}{|l|}{ Health variables } \\
\hline \multicolumn{5}{|l|}{ Health-related quality of life (SF-36, mean $(S D))$} \\
\hline Physical functioning & $87.1(15.1)$ & $83.3(17.3)$ & $91.8(10.3)$ & $0.093^{\mathrm{d}}$ \\
\hline Role limitations, physical & $73.8(38.0)$ & $68.8(39.6)$ & $79.8(35.3)$ & $0.403^{\mathrm{d}}$ \\
\hline Bodily pain & $69.8(26.4)$ & $62.9(27.6)$ & $78.1(22.3)$ & $0.053^{\mathrm{d}}$ \\
\hline General health & $72.6(21.1)$ & $67.3(21.9)$ & $79.1(18.0)$ & $0.051^{\mathrm{d}}$ \\
\hline Vitality & $55.7(20.3)$ & $50.1(18.0)$ & $62.4(21.1)$ & $0.016^{\mathrm{d}}$ \\
\hline Social functioning & $79.3(22.8)$ & $75.1(24.3)$ & $84.5(19.7)$ & $0.252^{\mathrm{d}}$ \\
\hline Role limitations, emotional & $77.0(36.4)$ & $71.6(39.3)$ & $83.6(31.5)$ & $0.441^{\mathrm{d}}$ \\
\hline Mental health & $73.8(15.2)$ & $70.7(14.1)$ & $77.6(15.6)$ & $0.066^{\mathrm{d}}$ \\
\hline Physical component score & $49.2(9.2)$ & $47.0(10.3)$ & $52.0(6.9)$ & $0.083^{\mathrm{d}}$ \\
\hline Mental component score & $48.2(10.0)$ & $46.8(10.3)$ & $49.8(9.4)$ & $0.329^{\mathrm{d}}$ \\
\hline Global Quality of life, mean (SD) & $71.6(19.5)$ & $67.5(19.9)$ & $76.9(17.7)$ & $0.231^{\mathrm{d}}$ \\
\hline \multicolumn{5}{|l|}{ Fatigue } \\
\hline Physical fatigue, mean (SD) & $9.1(2.9)$ & $9.6(2.9)$ & $8.5(2.9)$ & $0.257^{\mathrm{d}}$ \\
\hline
\end{tabular}




\begin{tabular}{|l|c|c|c|c|}
\hline Mental fatigue, mean (SD) & $\begin{array}{c}4.9(1.6) \\
14.0(4.1)\end{array}$ & $\begin{array}{c}5.1(1.7) \\
14.6(4.1)\end{array}$ & $\begin{array}{c}4.7(1.5) \\
13.2(3.9) \\
9(13)\end{array}$ & $\begin{array}{c}0.458^{\mathrm{d}} \\
0.270^{\mathrm{d}} \\
\text { Total fatigue, mean (SD) }\end{array}$ \\
Chronic fatigue, N (\%) & $34(21)$ & $25(28)$ & $9.036^{\mathrm{d}}$ \\
\hline Lifestyle & $95(59)$ & $50(56)$ & $45(63)$ & $0.858^{\mathrm{d}}$ \\
Overweight/obesity, N (\%) & $21(13)$ & $10(11)$ & $11(15)$ & $0.517^{\mathrm{d}}$ \\
Current smoker, N (\%) & $51(31)$ & $28(31)$ & $23(31)$ & $0.566^{\mathrm{d}}$ \\
Alcohol (frequent), N (\%) & $3.6(2.6)$ & $3.3(2.1)$ & $4.0(3.1)$ & $0.447^{\mathrm{d}}$ \\
Physical activity level, mean (SD) & & & & \\
\hline Influence on work situation and family life, N(\%) & $14(9)$ & $4(5)$ & $10(14)$ & $0.03^{\mathrm{d}}$ \\
\hline The partners' cancer disease has changed their work & & & & \\
situation & $71(44)$ & $32(36)$ & $39(53)$ & $0.05^{\mathrm{d}}$ \\
The partners' cancer disease has affected their family & & & & \\
life* & & & & \\
\hline
\end{tabular}

$\mathrm{N}$ may vary, due to missing variables: females range $82-92$, males range 65-75

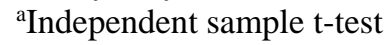

${ }^{\mathrm{b}} \mathrm{Chi}$-square test

${ }^{\mathrm{c} N o n-p a r a m e t r i c ~ M a n n-W h i t n e y ~ U ~ t e s t ~}$

'Adjusted for the partners' recurrence of cancer/metastasis and musculoskeletal diseases.

*To a large/very large extent 
Table 2. Comparison between female $(\mathrm{N}=68)$ and male $(\mathrm{N}=47)$ caregivers at follow-up

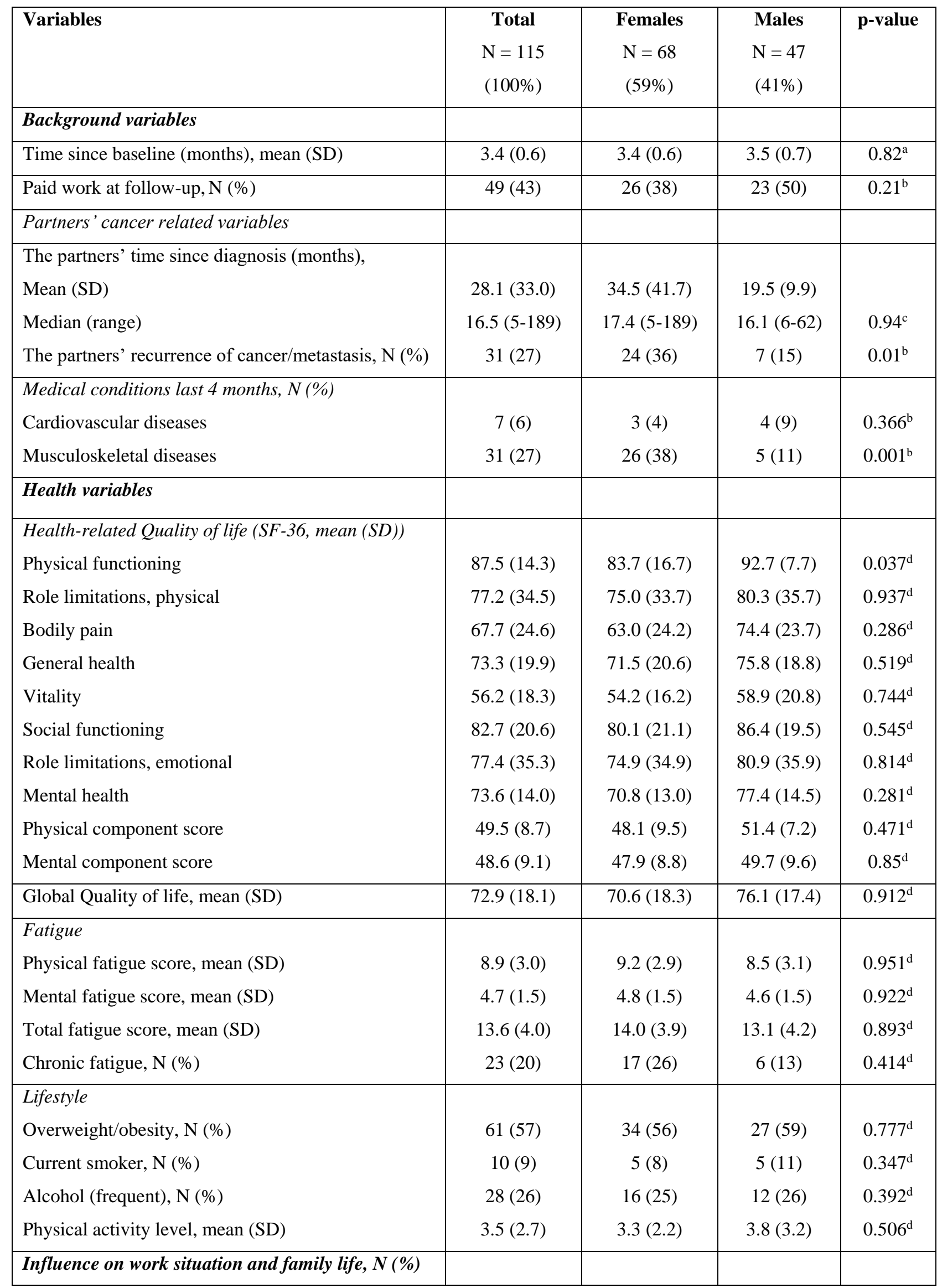




\begin{tabular}{|l|c|c|c|c|}
\hline $\begin{array}{l}\text { The partners' cancer disease has changed their work } \\
\text { situation }\end{array}$ & $10(10)$ & $2(3)$ & $8(18)$ & $0.055^{\mathrm{d}}$ \\
$\begin{array}{l}\text { The partners' cancer disease has affected their family } \\
\text { life* }\end{array}$ & $50(47)$ & $27(44)$ & $23(51)$ & $0.134^{\mathrm{d}}$ \\
\hline
\end{tabular}

$\mathrm{N}$ may vary, due to missing variables: females range $56-68$, males range $42-47$

${ }^{\text {a} I n d e p e n d e n t ~ s a m p l e ~ t-t e s t ~}$

${ }^{\mathrm{b}} \mathrm{Chi}$-square test

${ }^{\mathrm{c}}$ Non-parametric Mann-Whitney U test

${ }^{\mathrm{d}}$ Adjusted for the partners' recurrence of cancer/metastasis and musculoskeletal diseases.

*To a large/very large extent 
Table 3. Changes over time for female and male caregivers

\begin{tabular}{|c|c|c|c|c|}
\hline Variables & $\begin{array}{c}\text { Total } \\
\mathrm{N}=115 \\
(100 \%)\end{array}$ & $\begin{array}{c}\text { Females } \\
\mathrm{N}=68 \\
(59 \%)\end{array}$ & $\begin{array}{l}\text { Males } \\
\mathrm{N}=47 \\
(41 \%)\end{array}$ & p-value \\
\hline \multicolumn{5}{|l|}{ Background variables } \\
\hline Time since baseline (months), mean (SD) & $3.4(0.6)$ & $3.4(0.6)$ & $3.5(0.7)$ & $0.82^{\mathrm{a}}$ \\
\hline Paid work at follow-up, N (\%) & $49(43)$ & $26(38)$ & $23(50)$ & $0.21^{\mathrm{b}}$ \\
\hline \multicolumn{5}{|l|}{ Partners' cancer related variables } \\
\hline \multicolumn{5}{|l|}{ The partners' time since diagnosis (months), } \\
\hline Median (range) & $16.5(5-189)$ & $17.4(5-189)$ & $16.1(6-62)$ & $0.94^{\mathrm{c}}$ \\
\hline The partners' recurrence of cancer/metastasis, $\mathrm{N}(\%)$ & $31(27)$ & $24(36)$ & $7(15)$ & $0.01^{\mathrm{b}}$ \\
\hline \multicolumn{5}{|l|}{ Medical conditions last 4 months, $N(\%)$} \\
\hline Cardiovascular diseases & $7(6)$ & $3(4)$ & $4(9)$ & $0.366^{\mathrm{b}}$ \\
\hline Musculoskeletal diseases & $31(27)$ & $26(38)$ & $5(11)$ & $0.001^{\mathrm{b}}$ \\
\hline \multicolumn{5}{|l|}{ Health variables } \\
\hline \multicolumn{5}{|l|}{ Health-related Quality of life (SF-36, mean (SD)) } \\
\hline Physical functioning & $87.5(14.3)$ & $83.7(16.7)$ & $92.7(7.7)$ & $0.037^{\mathrm{d}}$ \\
\hline Role limitations, physical & $77.2(34.5)$ & $75.0(33.7)$ & $80.3(35.7)$ & $0.937^{\mathrm{d}}$ \\
\hline Bodily pain & $67.7(24.6)$ & $63.0(24.2)$ & $74.4(23.7)$ & $0.286^{\mathrm{d}}$ \\
\hline General health & $73.3(19.9)$ & $71.5(20.6)$ & $75.8(18.8)$ & $0.519^{\mathrm{d}}$ \\
\hline Vitality & $56.2(18.3)$ & $54.2(16.2)$ & $58.9(20.8)$ & $0.744^{\mathrm{d}}$ \\
\hline Social functioning & $82.7(20.6)$ & $80.1(21.1)$ & $86.4(19.5)$ & $0.545^{\mathrm{d}}$ \\
\hline Role limitations, emotional & $77.4(35.3)$ & $74.9(34.9)$ & $80.9(35.9)$ & $0.814^{\mathrm{d}}$ \\
\hline Mental health & $73.6(14.0)$ & $70.8(13.0)$ & $77.4(14.5)$ & $0.281^{\mathrm{d}}$ \\
\hline Physical component score & $49.5(8.7)$ & $48.1(9.5)$ & $51.4(7.2)$ & $0.471^{\mathrm{d}}$ \\
\hline Mental component score & $48.6(9.1)$ & $47.9(8.8)$ & $49.7(9.6)$ & $0.85^{\mathrm{d}}$ \\
\hline Global Quality of life, mean (SD) & $72.9(18.1)$ & $70.6(18.3)$ & $76.1(17.4)$ & $0.912^{\mathrm{d}}$ \\
\hline \multicolumn{5}{|l|}{ Fatigue } \\
\hline Physical fatigue score, mean (SD) & $8.9(3.0)$ & $9.2(2.9)$ & $8.5(3.1)$ & $0.951^{\mathrm{d}}$ \\
\hline Mental fatigue score, mean (SD) & $4.7(1.5)$ & $4.8(1.5)$ & $4.6(1.5)$ & $0.922^{\mathrm{d}}$ \\
\hline Total fatigue score, mean (SD) & $13.6(4.0)$ & $14.0(3.9)$ & $13.1(4.2)$ & $0.893^{\mathrm{d}}$ \\
\hline Chronic fatigue, $\mathrm{N}(\%)$ & $23(20)$ & $17(26)$ & $6(13)$ & $0.414^{\mathrm{d}}$ \\
\hline \multicolumn{5}{|l|}{ Lifestyle } \\
\hline Overweight/obesity, $\mathrm{N}(\%)$ & $61(57)$ & $34(56)$ & $27(59)$ & $0.777^{\mathrm{d}}$ \\
\hline Current smoker, N (\%) & $10(9)$ & $5(8)$ & $5(11)$ & $0.347^{\mathrm{d}}$ \\
\hline Alcohol (frequent), N (\%) & $28(26)$ & $16(25)$ & $12(26)$ & $0.392^{\mathrm{d}}$ \\
\hline Physical activity level, mean (SD) & $3.5(2.7)$ & $3.3(2.2)$ & $3.8(3.2)$ & $0.506^{\mathrm{d}}$ \\
\hline Influence on work situation and family life, $N(\%)$ & & & & \\
\hline
\end{tabular}




\begin{tabular}{|l|c|c|c|c|}
\hline $\begin{array}{l}\text { The partners' cancer disease has changed their work } \\
\text { situation }\end{array}$ & $10(10)$ & $2(3)$ & $8(18)$ & $0.055^{\mathrm{d}}$ \\
$\begin{array}{l}\text { The partners' cancer disease has affected their family } \\
\text { life* }\end{array}$ & $50(47)$ & $27(44)$ & $23(51)$ & $0.134^{\mathrm{d}}$ \\
\hline
\end{tabular}

$\mathrm{N}$ may vary, due to missing variables: females range $56-68$, males range $42-47$

${ }^{\text {a} I n d e p e n d e n t ~ s a m p l e ~ t-t e s t ~}$

${ }^{\mathrm{b}} \mathrm{Chi}$-square test

${ }^{\mathrm{c}}$ Non-parametric Mann-Whitney U test

${ }^{\mathrm{d}}$ Adjusted for the partners' recurrence of cancer/metastasis and musculoskeletal diseases.

*To a large/very large extent 


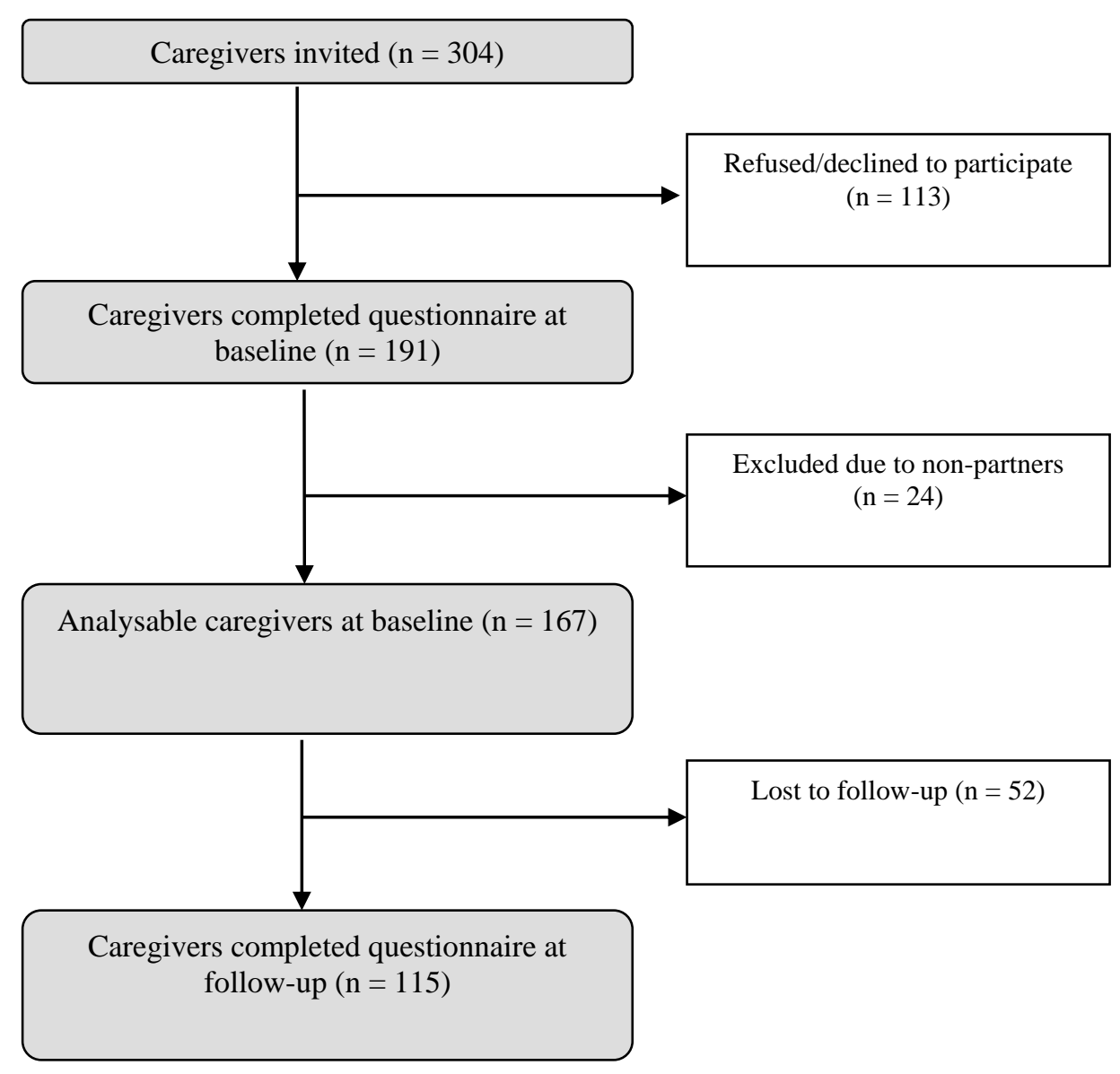

Figure 1. Flow chart of the participants through the study 


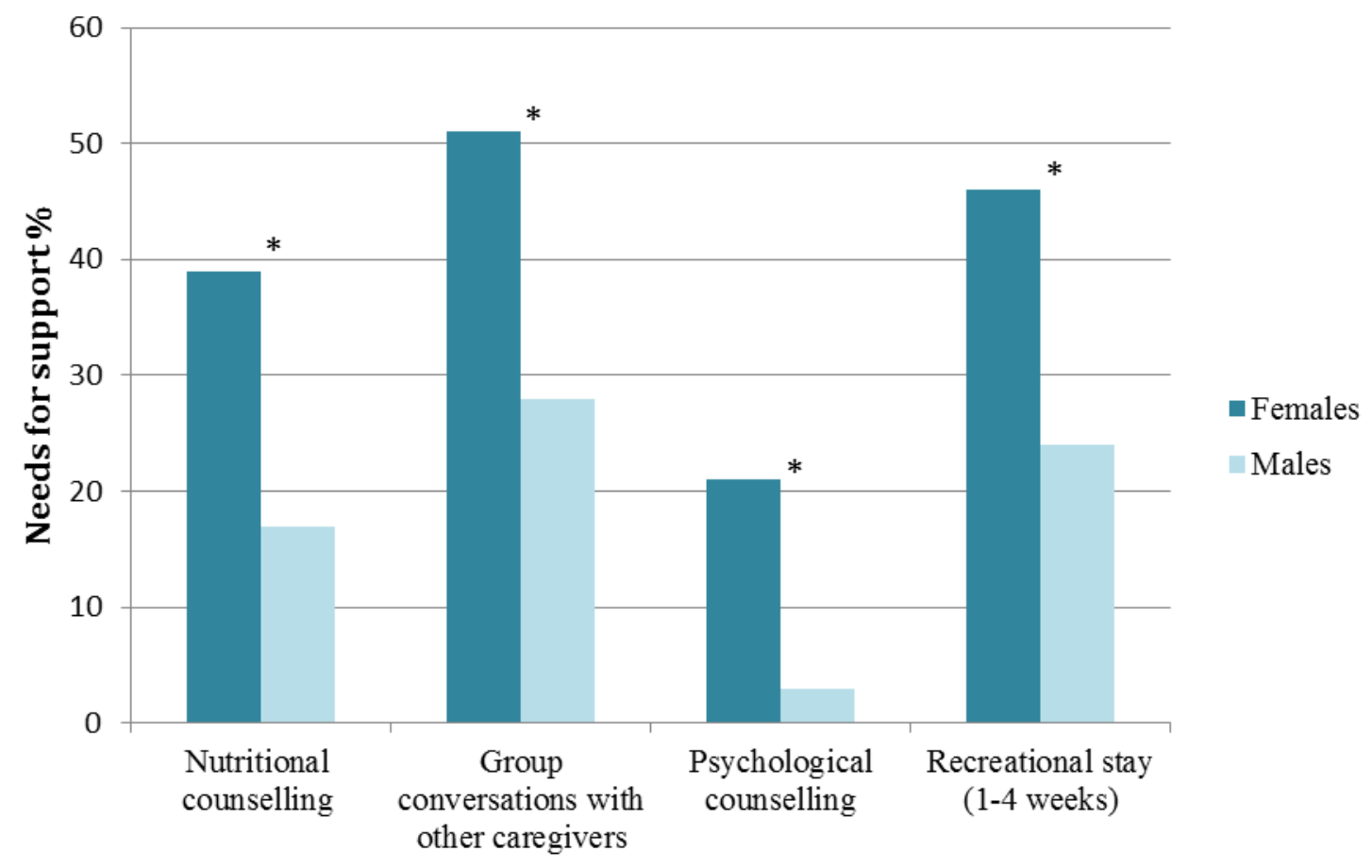

*All categories had significant differences between the genders $\mathrm{p}<0.05$. Analyzed with Chi-square test.

Figure 2. Proportions $(\%)$ of female $(n=92)$ and male $(n=75)$ caregivers who reported needs for support at baseline 